\title{
Effect of shelter on reproduction, growth and longevity of the German cockroach, Blattella germanica (Dictyoptera: Blattellidae)
}

\author{
CÉSAR GEMENO ${ }^{1}$, Gregory M. WILLIAMS² and COBy SCHAL ${ }^{3}$ \\ ${ }^{1}$ Department of Crop and Forest Sciences, University of Lleida, Lleida, 25198, Spain; e-mail: cesar.gemeno@pvcf.udl.cat \\ ${ }^{2}$ Mosquito and Vector Control Unit, Hudson Regional Health Commission, 595 County Ave., Bld. 1, Secaucus, \\ New Jersey, 07094, USA \\ ${ }^{3}$ Department of Entomology and W.M. Keck Center for Behavioral Biology, Box 7613, North Carolina State University, Raleigh, \\ North Carolina, 27695-7613, USA
}

Key words. Dictyoptera, Blattellidae, Blattela germanica, cockroach, shelter, fitness, population, aggregation, reproduction, growth, longevity

\begin{abstract}
German cockroaches spend most of the day in aggregations within shelters, which they leave in nocturnal foraging trips; cockroaches are rarely seen outside shelters during daylight hours. However, when population density exceeds shelter availability, diurnal aggregations form in exposed, unsheltered locations. To determine if shelter availability affects fitness of $B$. germanica, we reared cohorts of nymphs in laboratory arenas with or without shelters, and measured reproduction and longevity of tagged adults. When shelters were available in arenas, nymphs developed faster, adults gained more body mass, and females produced more fertile oothecae than when arenas lacked shelters. Therefore, shelter alone has a significant positive effect on growth and reproduction of $B$. germanica, and reducing or eliminating shelters should affect population growth of $B$. germanica in residential and industrial settings.
\end{abstract}

\section{INTRODUCTION}

Blattella germanica forages at night and spends the major part of the day hiding in narrow spaces (shelters or harborages) (Silverman, 1986; DeMark \& Bennett, 1994). Hiding within a shelter is probably an adaptation to reduce the risk of predation. Nonetheless, this behavior may confer other advantages such as providing favorable humidity and temperature conditions (Schal et al., 1984; Rust et al., 1995; Dambach \& Goehlen, 1999; Danks, 2002; Bell et al., 2007; Lihoreau \& Rivault, 2008). In addition, various social interactions of $B$. germanica are closely associated with the use of shelter - aggregation (Ishii \& Kuwahara, 1968; Wileyto et al., 1984), coprophagy and sharing of intestinal symbionts (reviewed for Dictyoptera by Nalepa et al., 2001), acoustic communication (Wijenberg et al., 2008), trail following (Miller \& Koehler, 2000; Jeanson \& Deneubourg, 2007), spatial orientation (Rivault \& Durier, 2004), and reproduction (Bret et al., 1983). Moreover, shelters and shelterassociated semiochemicals facilitate grouping of individuals, which in turn promotes faster growth and development in nymphs (Willis et al., 1958) and adults (Gadot et al., 1989). Despite the importance of shelters in the life-history of B. germanica, attempts to control its populations by limiting shelter availability have been unsuccessful (Farmer \& Robinson, 1984).

$B$. germanica nymphs and adults select shelters according to their size - first instars occupy the smallest shelters, and then move to larger ones as they molt and grow bigger, eventually sharing shelters with the adults (Koehler et al., 1994). The presence, developmental stage, and sex of conspecifics determine the distribution of aggregations in shelters (Koehler et al., 1994; Rivault \& Cloarec, 1998; Jeanson \& Deneubourg, 2007), and shelter fidelity has been demonstrated under natural conditions (Rivault, 1989). The use of shelter is not constant during each stadium or the light-dark cycle. In general, there is high activity during the first half of the stadium and during the night, and second instars spend $>90 \%$ of their time within shelters during the 2 to 3 days preceding the molt (DeMark \& Bennett, 1994). The distance between food and water sources and shelter affects the periodicity of foraging trips (Silverman, 1986; Koehler et al., 1994). Population density also affects shelter use. Under crowded conditions, B. germanica produces non species-specific repellent salivary proteins that may act as alarm or defensive semiochemicals and appear to antagonize the attractant and arrestant effects of aggregation pheromones (Ross \& Tignor, 1988). Recently, Wijenberg et al. (2008) reported that acoustic communication within shelters also might be important in guiding the formation and dissolution of German cockroach aggregations.

Despite the many studies on the use of shelter by German cockroaches, information about the effect of shelter on fitness is completely lacking. Several studies have estimated population growth parameters of B. germanica from whole populations (e.g., Reid, 1989), or from individual females (e.g., Hamilton \& Schal, 1990), but no study has compared these parameters from populations with and without access to shelters. The purpose of this study was to determine the effect of shelter availability on life history parameters of individual B. ger- 
manica. For this, we monitored cohorts of newly emerged nymphs throughout their lives in arenas provided with water and food ad libitum with or without shelters. The occupancy of shelters of three different sizes was recorded throughout development, and newly emerged adults were labeled individually, so that we could follow the reproductive output and longevity of adult males and females.

\section{MATERIAL AND METHODS}

\section{Insects}

A laboratory colony of insecticide-susceptible German cockroaches (American Cyanamid strain, Princeton, NJ) was maintained at $27^{\circ} \mathrm{C}$, ambient humidity, a photoperiod of $12 \mathrm{~L}: 12 \mathrm{D}$, and provided with water and Purina Rat Chow 5012 (Purina Mills, St. Louis, MO). Six-day-old virgin females and 13day-old virgin males from the laboratory colony, which are sexually receptive (Nishida \& Fukami, 1983; Schal \& Chiang, 1995), were paired until mated and observed every $10 \mathrm{~min}$ to ensure proper mating duration. Two days later, five mated males and females were placed in each of the eight test arenas. As first instars began to emerge $23 \mathrm{~d}$ later, their number was adjusted to 190 first instars per arena by adding and removing nymphs randomly among arenas. Successive oothecae from founding females were removed from the arenas. When the progeny started to eclose into adults the founding parents were removed from the arenas.

\section{Experimental arenas}

The arenas consisted of clear plastic cages $30-\mathrm{cm}$ wide, $60-\mathrm{cm}$ long and $30-\mathrm{cm}$ tall. The upper half of the inside walls was coated with a thin layer of a petroleum jelly:mineral oil mixture $(2: 1)$, and each arena was covered with grey nylon window mosquito screen. Four arenas were provided with shelters while the other four remained without shelters. Arenas with shelters contained twelve $7.5 \times 7.5 \times 0.4-\mathrm{cm}$ translucent, red plastic plates per arena, at different heights from the floor of the arena $(0-1.5 \mathrm{~mm}$, low shelter; $3 \mathrm{~mm}$, medium shelter; $4.5 \mathrm{~mm}$, high shelter). The shelters were separated from the floor of the arena with plastic pegs of the appropriate height placed under one (low shelter) or two sides (medium and high shelters). The low shelters, therefore, touched the floor of the arena on one side $(0 \mathrm{~mm})$ and were $1.5 \mathrm{~mm}$ from the floor on the opposite side. B. germanica spectral sensitivity has a peak at $490 \mathrm{~nm}$ (blue-green) and another at $365 \mathrm{~nm}$ (UV) (Koehler et al., 1987), so they are not sensitive to red light, and therefore the red plastic plates provided a darker environment for the cockroaches within the shelters while allowing us to observe them. There were four shelters of each height placed in random positions in each arena. No-shelter arenas were provided with 12 transparent-plastic plates per arena, of similar thickness and material as those in the arenas with shelter, but separated $2 \mathrm{~cm}$ from the floor with three $1-\mathrm{cm}$ wide legs per shelter, made of the same transparent-plastic material as the shelters. The spaces under these plates were inadequate as shelters because they were bright and the plates were too high. However, cockroaches could climb and walk on these transparent plates, which served to control for the added surface area provided by shelters in the arenas with shelter. Drinking water was provided in $125-\mathrm{ml}$ glass test tubes, one per arena, with a cotton plug to provide a drinking surface and the blunt end elevated $2 \mathrm{~cm}$ from the floor by a wire to minimize sheltering. Ground rat chow was provided in 4-cm-diameter $\times 1$-cm-high clear-plastic trays, one per arena, separated $2 \mathrm{~cm}$ from the floor with three clear-plastic legs to exclude them as shelters. Food and water were replaced as nec- essary. Arenas were placed in an environmental room $(27 \pm$ $\left.1{ }^{\circ} \mathrm{C}, 12 \mathrm{~L}: 12 \mathrm{D}\right)$ illuminated with ceiling-mounted fluorescent lights (180 lux inside the arenas). Arena position was rotated every week to control for possible environmental differences in the room.

\section{Nymphs}

The number of nymphs in each arena was recorded when most individuals reached the second instar, and on each successive molt, up to the adult stage. With time, the overlap among stadia increased, so observations were made when most of the nymphs in an arena were in the same instar. The first census (mainly second instars) was 13 to 15 days after hatch, the second census (mostly third instars) was on days 18 to 20 , the third census (third and fourth instars) was on days 26 to 30, and the fourth census (third to fifth instars) was on days 39 to 42 . The numbers of nymphs and adults in the different types of shelters in the arenas with shelters were also recorded. To count first to third instars we used an aspirator connected to a light vacuum, so that the nymphs were counted as they were removed, whereas older instars were collected individually by allowing them to walk into a glass tube. The handling procedure did not seem to injure the nymphs. After being counted, live nymphs were put back in the arena, and dead nymphs were discarded.

\section{Adults}

New adults were recorded daily, until all of them had emerged. New adults were (a) labeled individually and returned to the arenas to monitor their longevity and reproduction (38\%), or (b) marked by cutting the distal $2-3 \mathrm{~mm}$ of their forewings and returned to the arenas (34\%), or (c) removed from the arenas permanently to obtain dry body mass after drying them for $2 \mathrm{~d}$ at $60^{\circ} \mathrm{C}(28 \%)$. Labeled individuals were followed throughout their lifetime. Unlabeled individuals had to be marked to distinguish them from newly emerged individuals, and so the tips of their forewings were cut. Individuals were labeled with $3 \times 3 \mathrm{~mm}$ pieces of copier paper with numbers printed with a laser printer. Labels were glued on the anterior dorsum of a forewing with Elmer's Wonderbond Plus (Elmer's, Columbus, Ohio, USA), after $\mathrm{CO}_{2}$ anesthesia. Adults were monitored every $1-2$ days to record their longevity. Dead adults were removed from the arenas.

\section{Female reproduction}

Marked females were monitored throughout their lifetime to estimate their reproductive parameters. B. germanica females carry the ootheca externally attached to the genital atrium and at $27^{\circ} \mathrm{C}$ the nymphs hatched about 3 weeks after the ootheca was formed. Accordingly, each female was checked daily for presence of an ootheca, and 20 days after the ootheca was detected the female was removed from the arena in a glass tube and placed in a $125-\mathrm{ml}$ glass test tube sealed with a paper tissue and provided with a small vial of water and a piece of rat chow. When the nymphs hatched they were counted and returned to the arena together with the mother. This procedure was repeated for each successive egg case until the female died.

\section{Statistical analyses}

To determine if the presence of shelters had an effect on the survival of first instar nymphs (190 per arena, 760 total per treatment) to the adult stage, we performed a log-rank test (Bland \& Altman, 2004). To determine if shelter had an effect on the proportion of adult males and females we performed a $\chi^{2}$ test. For all other dependent variables the effects of shelter and sex were analyzed with $t$-tests (factor: shelter) and 2-Way ANOVAs (factors: shelter and sex). Because there were only 


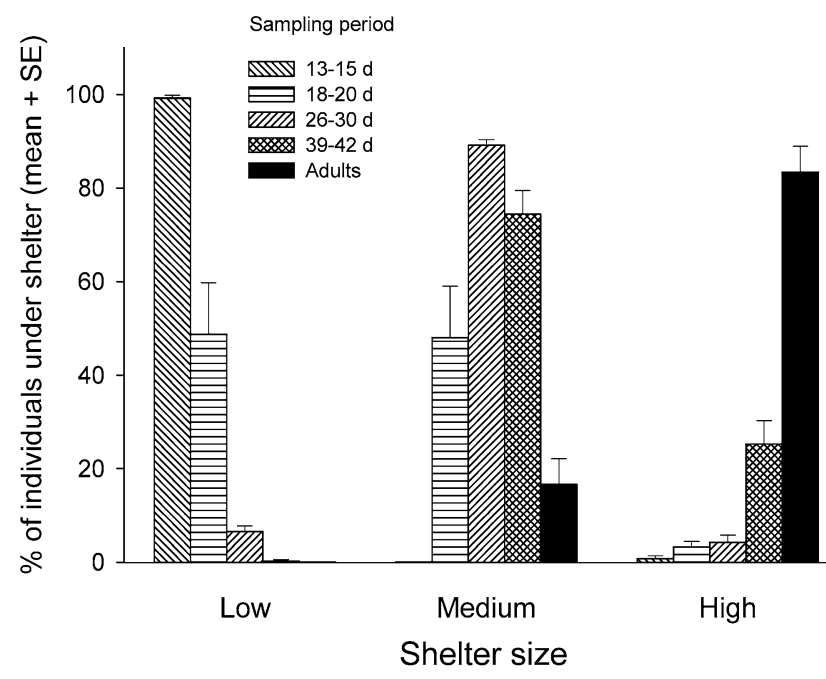

Fig. 1. Distribution of nymphs and adults of Blattella germanica in shelters of 3 different heights at different times during nymphal development. Shelter size: low 0-1.5 mm, medium $3 \mathrm{~mm}$, high $4.5 \mathrm{~mm}$. Nymphs and adults were sampled at approximately 1 -week intervals following emergence of $2^{\text {nd }}$ instars. Samples 1 and 2 (13-15 d and 18-20 d after hatching, respectively) consisted mainly of $2^{\text {nd }}$ and $3^{\text {rd }}$ instars, respectively. Samples 3 and 4 (26-30 d and 39-42 d, respectively) contained $3^{\text {rd }}$ to $5^{\text {th }}$ instars. Adult data include all 4 samples.

four arenas per treatment, and the results were similar among them, the data from the four arenas were pooled. Sample size represented the number of insects analyzed: For estimates of time (days) of nymphal development (hatch to adult emergence) $\mathrm{N}=292$ to 324 , for body mass and all the female reproductive parameters $\mathrm{N}=31$ to 39 , and for adult longevity $\mathrm{N}=80$ to 154 . Statistical tests were performed with $\mathrm{R}$ software (R Development Core Team, 2008).

\section{RESULTS AND DISCUSSION}

\section{Use of shelters}

In the arenas that contained shelters of various heights, $2^{\text {nd }}$ instars (sampled days 13-15 after hatch) used mainly the low shelters, $3^{\text {rd }}$ instars (sampled days 18-20) occupied the low and medium shelters, and older nymphs hid under the medium and high shelters (Fig. 1). Adults used the medium (only males) and high shelters (both males and females), but as the number of large nymphs increased and they started to occupy the medium shelters, males moved from the medium shelters to the high shelters. Koehler et al. (1994) reported size-segregation in $B$. germanica, but in their study small nymphs sheltered more in larger harborages when in mixed-age groups than in same-age groups; they speculated that chemical signals, produced by the older nymphs and adults in the larger harborages, might have attracted the small nymphs to the larger shelters. A similar phenomenon was observed by Jeanson \& Deneubourg (2007). In the former two studies, test insects were released into arenas free of conspecific odors, and their distribution in shelters was recorded within $24 \mathrm{~h}$, whereas in our study nymphs were released into arenas previously occupied by adults and the recording of shelter distribution commenced two weeks

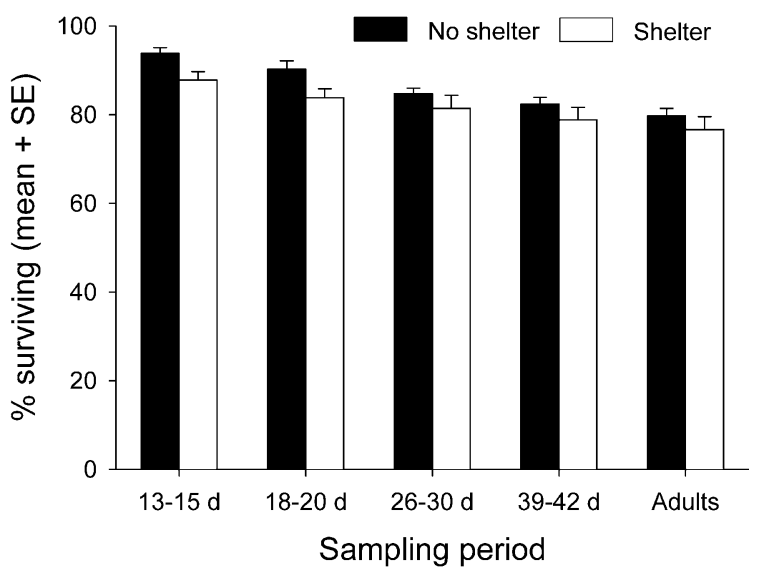

Fig. 2. Percentage of nymphs of Blattella germanica surviving at successive sampling periods up to adulthood in shelter and no-shelter arenas. Sample $1(13-15$ d) was performed when most $1^{\text {st }}$ instars had molted into $2^{\text {nd }}$ instars. Sample $2(18-20 \mathrm{~d})$ consisted mainly of third instars. Samples 3 and 4 (26-30 d and $39-42 \mathrm{~d}$, respectively) included $3^{\text {rd }}$ to $5^{\text {th }}$ instars. All the adults emerged from these nymphs were included in the adult class. Survival was similar between arenas with shelters and arenas without shelters (logrank, $\mathrm{P}>0.05)$.

after hatching. Our results indicate that, given enough time to distribute, smaller nymphs prefer the tighter shelters, independently of whether older individuals occupy the other shelters. However, pheromones are probably important in determining shelter selection, and long-term experiments designed to test this hypothesis - for example testing the odors of different age groups, sexes or mating status - are necessary.

In the arenas without shelters cockroaches rested alone or in small aggregations, mainly in the less illuminated areas of the arenas, with the small nymphs usually found in the darkest spots, i.e., underneath the food platform and the water vial. Adults often tried to climb up the walls, probably in search of shelter, a behavior that we rarely observed in arenas with shelters. Although females were constantly exposed in the no-shelter arenas, we did not observe males courting females any more than in the arenas with shelters. This could be the result of habituation or sensory adaptation of males to the continuous presence of the females when there is no shelter. In contrast, when shelters were removed during daytime to perform a census in the shelter arenas, males quickly courted the exposed females. Our observations suggest that in nature females may use small shelters (i.e., crevices) if they want to avoid male harassment, since males cannot raise their wings (part of the courtship sequence) in these narrow spaces. Shelter use by females is affected both by the reproductive state and the density of females in mixed-age populations. In females without an oötheca (i.e., vitellogenic and pre-oviposition phases) there is an inverse relationship between aggregation and density. Conversely, females that carry an oötheca aggregate more at greater densities (Bret et al., 1983). 
TABLE 1. Life history parameters of Blattella germanica reared from egg hatch in arenas with or without shelters (mean \pm SE). The presence of shelter in the test arenas reduced the number of days of nymphal development $(P<0.01)$, and produced heavier individuals $(P=0.02)$, but it did not affect adult longevity $(P=0.51)$. Females emerged earlier than males $(P=0.03)$, and were heavier and lived longer than males $(P<0.01)$. Statistical test: 2 -way ANOVA with sex and shelter as factors.

\begin{tabular}{|c|c|c|c|c|c|c|}
\hline & \multicolumn{2}{|c|}{ Days to adult emergence } & \multicolumn{2}{|c|}{ Dry body mass (mg) } & \multicolumn{2}{|c|}{ Longevity (days) } \\
\hline & Males & Females & Males & Females & Males & females \\
\hline Shelters & $52.0 \pm 0.17$ & $51.3 \pm 0.20$ & $12.6 \pm 0.18$ & $18.7 \pm 0.27$ & $119.3 \pm 1.96$ & $163.0 \pm 3.06$ \\
\hline No shelters & $55.9 \pm 0.25$ & $55.9 \pm 0.23$ & $12.2 \pm 0.13$ & $18.0 \pm 0.32$ & $126.6 \pm 1.98$ & $160.3 \pm 3.57$ \\
\hline
\end{tabular}

\section{Survival and growth}

The number of surviving nymphs decreased gradually in each successive sampling period, with no difference in survival curves between arenas with and without shelters (Fig. 2, log-rank $\chi_{(1)}^{2}=1.5, P=0.23$ ). Although food was provided ad libitum, exuviae and dead individuals were eaten almost completely in both shelter and no-shelter arenas occupied by first, second and third instars, but they accumulated in arenas occupied by later instars. We also observed several events of cannibalism on newly emerged, non-sclerotized (white) nymphs by adults and larger nymphs in both types of arenas. Under the unlimited food and water conditions of our tests, cannibalism may not have been an important factor providing an advantage within shelters. However under field conditions, where cannibalism has also been observed (Gahlhoff et al., 1999), food could be more limiting than in our test, and sheltering in small crevices may provide protection for newly hatched nymphs from cannibalism by large nymphs or adults.

Adult males and females emerged 4 days earlier in arenas with shelters than in arenas without shelters (Table 1) (ANOVA, $\left.F_{(1 ; 1,232)}=388.20, P<0.01\right)$. Females emerged earlier than males $\left(F_{(1 ; 1,232)}=4.88, P=0.03\right)$. The numbers of adult males and females (309 and 292, respectively, in shelter-arenas, and 324 and 299, respectively, in no-shelter-arenas) were independent of the presence of shelters $\left(\chi_{(1)}^{2}=0.02, P=0.88\right)$.

Shelters also had a positive effect on dry body mass: the adults in arenas with shelters were heavier than in arenas without shelters $\left(F_{(1,156)}=5.14, P=0.02\right)$. As expected, females were heavier than males, independent of shelter availability $\left(F_{(1,156)}=609.61, P<0.01\right)$ (Table 1). Light, air currents and other stress-related factors were probably more pronounced in the absence of shelters, which, in turn, may have contributed to the slower development and lower dry mass at emergence in the nonshelter situation. Nymphs grow faster if they are in groups than if they are alone (Willis et al., 1958; Lihoreau \& Rivault, 2008), so the higher aggregation promoted by shelters may have also contributed to the faster development of nymphs.
Females lived over 5 months while males lived significantly shorter, near 4 months $\left(F_{(1,420)}=184.89, P<0.01\right)$, but shelter had no effect on adult longevity $\left(F_{(1,420)}=0.44\right.$, $P=0.51)$ (Table 1$)$. These results are comparable to Hamilton \& Schal (1990), who reported female longevity of $176 \pm 5.7 \mathrm{~d}$, Willis et al. (1958) who reported $128 \mathrm{~d}$ for males and $153 \mathrm{~d}$ for females, and Reid (1989) who reported longevity of $139 \mathrm{~d}$ for males and $213 \mathrm{~d}$ for females.

\section{Female reproduction}

Females produced their first oötheca between 8 and 10 $\mathrm{d}$ after adult emergence, and significantly earlier in arenas with shelters than in no-shelter arenas $\left(t_{(46.88)}=3.04 P<\right.$ 0.01 ) (Table 2). In addition, more oöthecae were produced per female when there were shelters than in the absence of shelters $\left(t_{(56.44)}=2.83, P<0.01\right)$, and the number of fertile oöthecae per female was also higher in arenas with shelters than in the no-shelter arenas $\left(t_{(58.70)}=\right.$ $2.01, P=0.04)$. The number of nymphs hatched per fertile oötheca was similar between treatments, ca. $35\left(t_{(57.24)}\right.$ $=1.26, P=0.20$ ), and the time between successive oöthecae, from the first to the sixth, increased with each successive oötheca $\left(F_{(4,196)}=94.5, P<0.01\right)$, independently of the presence or absence of shelters $\left(F_{(1,196)}=1.52, P=\right.$ $1.22)$. The total number of nymphs produced by each female also was independent of shelters $\left(t_{(58.69)}=1.24, P=\right.$ $0.22)$.

Although more fertile oöthecae were produced in the presence of shelters, they did not result in more nymphs per female compared to the no-shelter treatment. However, there are reasons to posit that under field conditions more fertile oöthecae would result in more nymphs. In our experiment, females emerged before males (Table 1), and so the new females probably had a small pool of sexually mature males available to mate; B. germanica, unlike some other cockroaches, does not reproduce parthenogenetically. It is likely then, that the males that matured earlier mated repeatedly and fertilized many of the virgin females. Because accessory reproductive glands and testes take time to replenish (Gillot, 2003), the ability of a male to fertilize all the eggs of a female may

TABLE 2. Reproductive parameters of Blattella germanica females reared from egg hatch in arenas with or without shelters (mean \pm SE). Different letters in the same column indicate significant differences between treatments $(t$-test, $P<0.05)$.

\begin{tabular}{cccccc}
\hline & $\begin{array}{c}\text { Days to } \\
1^{\text {st }} \text { oötheca }\end{array}$ & $\begin{array}{c}\text { Oöthecae } \\
\text { per female }\end{array}$ & $\begin{array}{c}\text { Fertile oöthecae } \\
\text { per female }\end{array}$ & $\begin{array}{c}\text { Nymphs } \\
\text { per fertile oötheca }\end{array}$ & $\begin{array}{c}\text { Total nymphs } \\
\text { per female }\end{array}$ \\
\hline Shelters & $8.5 \pm 0.16 \mathrm{~b}$ & $5.4 \pm 0.20 \mathrm{a}$ & $4.7 \pm 0.25 \mathrm{a}$ & $34.9 \pm 0.97 \mathrm{a}$ & $164 \pm 8.67 \mathrm{a}$ \\
No shelters & $9.5+0.28 \mathrm{a}$ & $4.4 \pm 0.25 \mathrm{~b}$ & $4.1 \pm 0.23 \mathrm{~b}$ & $36.8 \pm 1.18 \mathrm{a}$ & $148 \pm 9.47 \mathrm{a}$ \\
\hline
\end{tabular}


have decreased on each successive mating, and so the number of fertilized eggs per oötheca (but see Lihoreau \& Rivault, 2010). In contrast, field populations of $B$. germanica are composed of mixed-age classes (Rust et al., 1995), and receptive females may have more opportunities to mate with males having full accessory reproductive glands and testes than in our experiment.

The adult body mass differences observed in our study for both males and females in shelter and no-shelter arenas might be even more pronounced under natural conditions, where food and water are more limited than in our experiment. Since female fertility in insects is generally correlated with body mass, a larger female size when shelter is present under natural conditions may result in more progeny and higher fitness.

Females exhibited behaviors that suggest that they protected the newly emerged nymphs, as reported by Cornwell (1968). Empty egg cases were normally observed outside and away from shelters, so perhaps females left the aggregations when nymphs were ready to hatch, and by doing so they could reduce the probability that nymphs would be cannibalized. Furthermore, females adopted a special posture around the time of nymph birth: they extended their legs, increasing the distance between the egg case and the ground, and remained motionless in this position for the duration of hatching, even when other individuals approached and bit or courted them. Finally, newly emerged nymphs aggregated around their stationary mother until they could run, and then they quickly ran toward a shelter. It is likely that these female behaviors are adaptations to increase neonate survival, but this is awaiting experimental demonstration. Other forms of maternal investment occur in B. germanica, including the provision of water (Roth \& Willis, 1955; Mullins et al., 2002), urates (Mullins \& Keil, 1980), and cuticular hydrocarbons (Fan et al., 2008).

\section{CONCLUSSIONS}

Shelters affect several developmental and reproductive parameters of $B$. germanica. In arenas with shelters the nymphs develop faster, they gain more body mass and the adults are heavier, and the females produce more fertile oöthecae. Although some of these disparities are small, individuals that occupy shelters would experience greater fitness, leading to greater shelter use in future generations, and a concomitant increase in population growth rate. Selection should favor the use of shelters even in the absence of predators, if environmental factors (e.g., temperature, relative humidity) and biological factors (e.g., cannibalism) within shelters are more favorable. When shelter is available, individuals probably spend less time and energy moving during daytime because they are more protected from environmental factors such as light, air currents and temperature fluctuations. Indoor cockroaches shun air currents (Appel \& Smith, 1999), probably because air movements and higher temperatures dehydrate the cockroach and its oötheca outside shelters, requiring more foraging trips to obtain water.
Abundant shelter provides cockroaches appropriate environments in which to grow, reproduce, and engage in nutrient and symbiont exchanges. It has been recognized in the pest control industry that inadequate maintenance of structures (e.g., apartments, restaurants) and indoor clutter, which make available more shelters, are conducive to establishment and expansion of chronic cockroach infestations. Surprisingly however, while shelter elimination is considered essential for Integrated Pest Management implementation, there is little evidence that dramatic improvement of sanitary conditions alone can either reduce established cockroach populations (Owens, 1980; Bertholf, 1983) or prevent the establishment of infestations. Moreover, Farmer \& Robinson (1984) found that limiting the amount of shelter did not affect the efficacy of insecticides on B. germanica populations. Our study suggests that the effects of limiting shelter are small, slow, and require one or more generations to become apparent. Nevertheless, various studies that have eliminated shelters, improved sanitary conditions, and applied a direct pest control measure (e.g., baits, residual insecticides) have found greater population reductions when less shelter is available, suggesting that shelter reduction or elimination can enhance the efficacy of other control measures.

ACKNOWLEDGEMENTS. We thank R. Sciabica and J. McAfee for technical help. This project was supported in part by the National Research Initiative of the USDA National Institute of Food and Agriculture grant number 2004-35302-14880, the Risk Avoidance and Mitigation Program of the USDA-NIFA grant number 2005-51101-02388, the Blanton J. Whitmire endowment at North Carolina State University, and a scholarship from the North Carolina Pest Management Association.

\section{REFERENCES}

Appel A.G. \& Smith L.M. II. 1999: Perception and repellency of moving air by American and smokybrown cockroaches (Dictyoptera: Blattellidae). J. Econ. Entomol. 92: 170-175.

Bell W.J., Roth L.M. \& Nalepa C. 2007: Cockroaches: Ecology, Behavior and Natural History. The Johns Hopkins University Press, Baltimore, Maryland, $230 \mathrm{pp}$.

BERTHOLF J.K. 1983: The Influence of Sanitation on German Cockroach Populations. Ph.D. dissertation, Purdue University, West Lafayette, Indiana, $71 \mathrm{pp}$.

Bland J.M. \& Altman D.G. 2004: The logrank test. Br. Med. J. 328: 1073.

Bret B., Ross M.H. \& Holtzman G.I. 1983: Influence of adult females on within-shelter distribution patterns of Blattella germanica (Dictyoptera: Blattellidae). Ann. Entomol. Soc. Am. 76: 847-852.

Cornwell P.B. 1968: The Cockroach. Vol. 1. Associated Business Programs, London, $391 \mathrm{pp}$.

Dambach M. \& Goehlen B. 1999: Aggregation density and longevity correlate with humidity in first instar nymphs of the cockroach Blattella germanica L. (Dictyoptera). J. Insect Physiol. 45: 423-429.

DANKS H.V. 2002: Modification of adverse conditions by insects. Oikos 99: 10-24.

DeMark J.J. \& Bennett G.W. 1994: Diel activity cycles in nymphal stadia of the German cockroach (Dictyoptera: Blattellidae). J. Econ. Entomol. 87: 941-950. 
Fan Y., EliYahu D. \& Schal C. 2008: Cuticular hydrocarbons as maternal provisions in embryos and nymphs of the cockroach Blattella germanica. J. Exp. Biol. 211: 548-554.

FARMER B.R. \& ROBINSON W.H. 1984: Harborage limitation as a component of a German cockroach pest management program (Dictyoptera: Blattellidae). Proc. Entomol. Soc. Wash. 86: 269-273.

Gadot M., Burns E. \& Schal C. 1989: Juvenile hormone biosynthesis and oocyte development in adult female Blattella germanica: effects of grouping and mating. Arch. Insect Biochem. Physiol. 11: 189-200.

Gahlfoff J.E. JR., Miller D.M. \& Koheler P.G. 1999: Secondary kill of adult male German cockroaches (Dictyoptera: Blattellidae) via cannibalism of nymphs fed toxic baits. J. Econ. Entomol. 92: 1133-1137.

GILLOT C. 2003: Male accessory gland secretions: modulators of female reproductive physiology and behaviour. Annu. Rev. Entomol. 48: 163-184.

Hamilton R.L. \& Schal C. 1990: Sublethal effects of chlorpyrifos-methyl on reproduction in female German cockroaches (Dictyoptera: Blattellidae). J. Econ. Entomol. 83: 441-443.

IshII S. \& KUWAHARA Y. 1968: Aggregation of German cockroach Blattella germanica nymphs. Experientia 24: $88-89$.

Jeanson R. \& Deneubourg J.-L. 2007: Conspecific attraction and shelter selection in gregarious insects. Am. Nat. 170: 47-58.

Koehler P.G., Agee H.R., Leppla N.C. \& Patterson R.S. 1987: Spectral sensitivity and behavioral response to light quality in German cockroach (Dictyoptera: Blattellidae). Ann. Entomol. Soc. Am. 80: 820-822.

Koenler P.G., Strong C.A. \& Patterson R.S. 1994: Harborage width preference of German cockroach (Dictyoptera: Blattellidae) adults and nymphs. J. Econ. Entomol. 87: 699-704.

Lihoreau M. \& Rivault C. 2008: Tactile stimuli trigger group effects in cockroach aggregations. Anim. Behav. 75: 1965-1972.

Lihoreau M. \& Rivault C. 2010: German cockroach males maximize their inclusive fitness by avoiding mating with kin. Anim. Behav. 80: 303-309.

Miller D.M. \& Koehler P.G. 2000: Trail-following behavior in the German cockroach (Dictyoptera: Blattellidae). J. Econ. Entomol. 93: 1241-1246.

Muluins D.E. \& KeIL C.B. 1980: Paternal investment of urates in cockroaches. Nature 283: 567-569.

Muluins D.E., Mullins K.J. \& TignoR K.R. 2002: The structural basis for water exchange between the female cockroach (Blattella germanica) and her oötheca. J. Exp. Biol. 205: 2987-2996.

Nalepa C.A., Bignell D.E. \& Bandi C. 2001: Detritivory, coprophagy, and the evolution of digestive mutualisms in Dictyoptera. Insectes Soc. 48: 194-201.
Nishida R. \& FuKami H. 1983: Female sex pheromone of the German cockroach, Blattella germanica. Mem. College Agric. Kyoto Univ. 122: 1-24.

Owens J.M. 1980: Some Aspects of German Cockroach Population Ecology in Urban Apartments. Ph.D. dissertation, Purdue University, West Lafayette, Indiana, $116 \mathrm{pp}$.

R Development Core Team 2008: R: A Language and Environment for Statistical Computing. $R$ Foundation for Statistical Computing, Vienna, Austria. ISBN 3-900051-07-0, URL http://www.R-project.org.

ReID B.L. 1989: The Dynamics of Laboratory Populations of the German Cockroach, Blattella germanica (L.), and the Influence of Juvenoids on their Population Dynamics. Ph.D. dissertation, Purdue University, West Lafayette, Indiana, USA, $97 \mathrm{pp}$.

Rivault C. 1989: Spatial distribution of the cockroach, Blattella germanica, in a swimming-bath facility. Entomol. Exp. Appl. 57: 85-91

Rivault C. \& Cloarec A. 1998: Cockroach aggregation: discrimination between strain odours in Blattella germanica. Anim. Behav. 55: 177-184.

Rivault C. \& Durier V. 2004: Homing in German cockroaches, Blattella germanica (Insecta: Dictyoptera): Multi-channeled orientation cues. Ethology 110: 761-777.

Rотн L.M. \& WiLlis E.R. 1955: Relation of water loss to the hatching of eggs from detached oöthecae of Blattella germanica (L.). J. Econ. Entomol. 48: 57-60.

Ross M.H. \& TIGNOR K.R. 1988: Differences in repellency of substances secreted by Blattella germanica (Dictyoptera: Blattellidae) females during the first week postecdysis. Ann. Entomol. Soc. Am. 81: 362-364.

Rust M.K., Owens J.M. \& REIERSON D.A. 1995: Understanding and Controlling the German Cockroach. Oxford University Press, Oxford, $448 \mathrm{pp}$.

Silverman J. 1986: Adult German cockroaches (Orthoptera: Blattellidae) feeding and drinking behavior as a function of density and harborage-to-resource distance. Environ. Entomol. 15: 198-204.

Schal C. \& Chiang A.-S. 1995: Hormonal control of sexual receptivity in cockroaches. Experientia 51: 994-998.

Schal C., Gautier J.-Y. \& Bell W.J. 1984: Behavioural ecology of cockroaches. Biol. Rev. 59: 209-254.

Wijenberg R., TaKács S., Cook M. \& Gries G. 2008: Female German cockroaches join conspecific groups based on the incidence of auditory cues. Entomol. Exp. Appl. 129: 124-131.

Wileyto E.P., Boush M. \& Gawin L.M. 1984: Function of cockroach (Orthoptera: Blattidae) aggregation behavior. Environ. Entomol. 13: 1557-1560.

Willis E.R., Riser George R.R. \& Roth L.M. 1958: Observations on reproduction and development in cockroaches. Ann. Entomol. Soc. Am. 51: 53-69.

Received August 13, 2010; revised and accepted November 4, 2010 